How to cite this article:

Jan, A., Samuel, M. S., \& Shafiq, A. (2020). Pedagogical practices of languages other than English teachers: A case study of a Malaysian private university. Malaysian Journal of Learning \& Instruction, 17(1), 77-99. https:// doi.org/10.32890/mjli2020.17.1.4

\title{
PEDAGOGICAL PRACTICES OF LANGUAGES OTHER THAN ENGLISH TEACHERS: A CASE STUDY OF A MALAYSIAN PRIVATE UNIVERSITY
}

\author{
${ }^{1}$ Anbareen Jan, ${ }^{2}$ Moses Stephens Samuel \& ${ }^{3}$ Ali Shafiq \\ ${ }^{1-2}$ School of Education, Taylors University Lakeside Campus, \\ Subang Jaya, Selangor, Malaysia \\ ${ }^{3}$ Faculty of Business and Law, Taylors University Lakeside \\ Campus, Subang Jaya, Selangor, Malaysia \\ ${ }^{l}$ Corresponding author: jananbareen@sd.taylors.edu.my
}

Received: 13/9/2019 Revised: 30/11/2019 Accepted: 22/12/2019 Published: 31/1/2020

\begin{abstract}
Purpose - Internationalization of education has made it important to have not only a command of English as a global language, but also of Languages Other Than English (LOTEs), which can be a second, national or heritage language. This narrative inquiry explored LOTE teachers' perspectives on their use of English and other pedagogical practices for teaching LOTE to international students.

Methodology - Narratives of three language teachers from different linguistic and cultural backgrounds, teaching French, Korean and Mandarin at a private university in Malaysia were recorded. Their discussion addressed key issues in teaching LOTE such as teaching strategies, use of technology and the importance of using English for teaching LOTEs. Data was analysed using Nvivo, applying Saldana's (2016) coding technique, consisting of structural, descriptive and values coding. 48 codes emerged during the first cycle coding, which were placed under nine categories in the second and final coding process.
\end{abstract}


Findings - Data revealed that for achieving practical outcomes, technologically integrated teaching is an alternative to traditional teaching practices. Further, teachers' narratives also showed the importance of English in LOTE teaching, owing to the internationalization of education.

Significance - The study explored LOTE pedagogy through the narratives of teachers, who are key stakeholders. The findings will help LOTE teachers reflect on their own teaching practices, and familiarize them with current pedagogy, including technology integration. They would also be useful in other contexts where LOTE is offered as a foreign language.

Keywords: Languages other than English, pedagogical strategies, technology integrated classrooms, teacher narratives.

\section{INTRODUCTION}

Language is the main obstacle that students face in international classrooms (Trahar, 2014). Research has shown that English is used as a common language between speakers who do not share a native language (Turnbull, 2018). Due to its importance, it is widely accepted that English plays a mediating role in the teaching and learning of LOTE (Armstrong \& Laksana, 2016; Finardi \& Rojo, 2015; Turnbull, 2018). Furthermore, the high motivation to learn LOTE takes place in juxtaposition with English language (Dörnyei \& Al-Hoorie, 2017; McEown, Sawaki, \& Harada, 2017). While the role of English in the teaching of LOTE cannot be denied, it has been reported that the same language is a source of interference (Henry, 2010) and a reason for low motivation to learn LOTE (Gayton, 2016).

In light of this dilemma, pedagogical strategies and perspectives of LOTE teachers should be explored. While many studies have been conducted on pedagogical strategies adopted in EFL and ESL classrooms, there remains a lack of research on teaching practices in the LOTE classroom. It has been found that teaching LOTE is different from teaching English or content subjects (Brown, 2009). Cases have been reported on the teaching of French and Spanish in Canada and Britain (Gayton, 2016; Kramsch, 2017), and Japanese 
and Chinese in Japan and China (Bartlett, 2017; Turnbull, 2018) respectively, where teachers were the only contributors to the target language. However, the situation might differ in Malaysia, as the learning objectives, instructional materials and approaches may diverge because of the exposure to foreign languages.

\section{Use of English in Teaching Foreign Languages}

Until the nineteenth century, the general belief was that in target language classrooms, students should not be encouraged to communicate in their native language (Hall \& Cook, 2012). Nevertheless, twentieth century literature in this area was not in favour of monolingual teaching, and accepted that using students' native language (L1) in the educational context had its advantages (Hall \& Cook, 2012). While the monolingual teaching technique can be adopted for teaching ESL or EFL because of the lingua franca status of English, the same monolingual assumption may not stand effective for teaching LOTE.

More recent researchers have reported cases where teachers have used, for pedagogical purposes, language(s) in which they lacked good proficiency. For example, in a multilingual classroom where the teacher's first language was French (Pugh, 2013) and Maltese (Xerri, 2016), the English language was still used for interactional purposes with multilingual students despite the teachers' lack of English proficiency. A study by Thompson and Harrison (2014) that focused on Spanish as a foreign language being taught in English (L1) classrooms concluded that a teacher's teaching methodology, education level, professional experience, field of study, cultural background, and native language influenced classroom strategies.

Related research in Malaysia has focused mainly on the mediation of Bahasa Melayu in the teaching of English (Lee, 2010; Romli \& Aziz, 2015 , Sua \& Raman, 2007). The studies have focused on the role of students' language, and on classrooms that have adopted different multilingual practices for teaching (Macalister, 2017; Nor, Leong, $\& \mathrm{Ka}, 2017)$. However, the existing literature has not addressed the role of English in the teaching of LOTE. In the context of LOTE, a study conducted in Australia has found that English impacts on the teaching of Chinese (Liu \& Bianco, 2007). However, no such research has been observed in the Malaysian context. 


\section{Pedagogical Practices}

In most LOTE classrooms, pedagogical practices are always taken for granted and teachers adopt the same instructional practices designed for teaching other subjects (Kramsch, 2014). Nonetheless, pedagogical practices for the teaching of English or other target languages can be implemented for teaching LOTE, although teaching LOTE is different from teaching English (Duff, 2017; Turnbull, 2018). In most cases, it has been highlighted that insufficient time is allotted to the teaching of LOTE and the language remains dormant for longer periods (Collins \& Munoz, 2016; Ushioda, 2017). Tognini (2008) states that longer interactive sessions and communicative use of language can help in effective teaching of LOTE.

A number of studies have investigated students' perspective on the use of L1 in learning foreign languages (Bartlett, 2017; Thompson \& Harrison, 2014; Turnbull, 2018) as well as the pedagogical practices in the English classroom (Chun, Kern, \& Smith, 2016; Haukås, 2016), but very few studies have looked at the use of English in the teaching of foreign languages (Brown, 2009; Anh, 2010), or the teaching strategies of LOTE teachers, such as Mandarin teachers (Hangyan, 2016; Nel, 2016). Hence, there is a need to explore teachers' perspectives on the use of English and their pedagogical practices for teaching LOTE. Similarly, while research has shown the effectiveness of technology integrated teaching at school level (Tan \& Abbas, 2009), the integration of technology for teaching LOTE has not been addressed.

\section{Significance of the Study}

Given the importance of English in the teaching of LOTE, this study is of significance for two reasons. Firstly, there is a general consensus in the literature urging researchers to explore the use of English in teaching LOTE (Dörnyei \& Al-Hoorie, 2017; Ushioda, 2017), as clear from similar research done in EFL settings (Turnbull, 2001; Duff, 2017; McEown, Sawaki, \& Harada, 2017). Teachers' narratives facilitate in exploring the relevance and use of English for teaching LOTE (Edwards, 2007; Duff, 2017). Secondly, technology-enhanced teaching and communicative approaches have been adopted for teaching English but the relevance of technologyintegrated teaching for LOTE has been an unexplored area. Hence, this study contributes to knowledge from the perspective of teachers, who are the most effective stakeholders, for the benefit of LOTE researchers and educators. 


\section{RESEARCH METHODOLOGY}

\section{Theoretical Background}

Grounded in constructivist theory, narratives enable the exploration of LOTE teachers' pedagogical strategies, as in-depth analysis helps in better understanding teachers' cognition and classroom practices (Cross, 2010). Furthermore, Vygotsky's sociocultural theory posits that social interaction plays a vital role in cognitive development as we mediate our social interaction with the world with the help of language, a cognitive tool of thought. Literature has shown that the use of the L1 improves target language learning and helps in understanding cross-cultural communication. Using two languages interchangeably, as in the use of L1 in ESL or switching from one to another for clarification purposes, also results in better learning. Hence, this study employed Vygotsky's 1962 sociocultural theory, the foundation of constructivism (Jaramillo, 1996; Steiner \& Mahn, 1996), which posits that the use of the L1 by the teacher during classroom interaction serves pedagogical functions. Similarly, the use of a common language or in this case, the lingua franca, holds importance in teaching LOTE. Thus, based on constructivism, teachers' use of English in teaching LOTE was explored through their narratives.

\section{Research Design}

By taking the epistemological stance of Stake (1995) and Merriam (2009), the constructivist paradigm was used for this research to gain a deeper understanding of the social phenomenon under study (Yin, 2011). Our role in this study was of interpreters, who were interested in understanding meaning or knowledge as constructed by people (Hunter, 2010; Yazan, 2015).

\section{Narrative Interviews}

The purpose of using narratives is to address theoretical and practical matters in education (Webster \& Mertova, 2007). Therefore, for exploring teachers' pedagogical practices, LOTE teachers' narratives were used (Moen, 2006), being "a natural tool for the L2 researcher" (Bell, 2002, p.211). Hollway and Jefferson, as cited in Elliott (2005), suggested that two interviews with each participant fulfilled the conditions of a narrative approach. Keeping this in mind, each participant was interviewed twice. Thus, in total 6 narrative 
interviews were conducted (see Charmaz, 2006; Creswell, 2007; Marshall, Cardon, Poddar, \& Fontenot, 2013; Morse, 2000) with three participating teachers. Moreover, in order to better interpret the interviews, some demographic information was also obtained from the respondents.

\section{Ethical Consideration}

An email with an enclosed individual interview consent form was sent to each participant. After obtaining consent, the interview schedule was arranged. To keep their identities confidential, the participants were coded T1, T2 and T3. For conformability, the analysis of the study was shared with the participants to ensure that the findings were supported by interview data.

\section{Research Site and Participants}

The research site was a private university in Malaysia with a significant number of international faculty and students; English was the medium of communication as well as instruction. The participants, i.e., 1 male and 2 female teachers, were selected from the Schools of Liberal Arts and Social Sciences based on 3 criteria: (1) the faculty member should be teaching LOTE, (2) their first language should not be English, and (3) they should be teaching LOTE to international students (see Table 1).

Table 1

Participants' Data Log

\begin{tabular}{|c|c|c|c|c|c|c|}
\hline Teacher & Gender & $\begin{array}{l}\text { Native } \\
\text { Language }\end{array}$ & $\begin{array}{l}\text { Teaching } \\
\text { experience }\end{array}$ & $\begin{array}{l}\text { Other languages } \\
\text { participant is able } \\
\text { to communicate in }\end{array}$ & $\begin{array}{l}\text { Language } \\
\text { expertise }\end{array}$ & $\begin{array}{l}\text { Number of } \\
\text { interviews }\end{array}$ \\
\hline $\mathrm{T} 1$ & F & Hakka & 12 years & $\begin{array}{l}\text { English; Bahasa } \\
\text { Melayu }\end{array}$ & French & 2 \\
\hline $\mathrm{T} 2$ & F & Korean & 6 years & English; Mandarin & Korean & 2 \\
\hline T3 & $\mathrm{M}$ & Cantonese & 10 years & $\begin{array}{l}\text { Bahasa Melayu; } \\
\text { English }\end{array}$ & Mandarin & 2 \\
\hline
\end{tabular}

\section{Data Collection}

In-depth unstructured interviews were carried out with the three LOTE teachers during the Spring 2019 semester. The interviews 
were conducted solely in English and each session lasted 60-80 minutes. The unstructured interviews followed some basic questions but most of the questions emerged as the interviews progressed (Elliott, 2005). After the first interview, open coding was done and the questions that emerged from the first interview were added to the existing ones and subsequently asked. Likewise, questions were added or excluded based on participants' first narrative. Field notes were taken and audio recordings were made during each interview session.

\section{Data Analysis}

Nvivo 12 was used for generating open codes from the interviews. In the first cycle coding process, 48 codes emerged, including Invivo codes (Saldana, 2016). Once open coding was done, the same codes were categorized, thus completing the second cycle coding (Saldana, 2016). This process was followed by thematic analysis (Hunter, 2010), where structural coding was done by categorizing interview transcripts based on the pedagogical strategies found in the literature, and descriptive coding was used to generate themes from the narratives. The following section discusses the categories which emerged from the coding process.

\section{RESULTS AND DISCUSSION}

The narratives showed that English was the dominant language for teaching, but at the same time it was considered a hindrance in the smooth and effective learning of LOTE. Participating teachers agreed that English was a global language and could be used for all kinds of instruction, although they unanimously favoured monolingual teaching. Participants reflected on their teaching practices, and faceto-face teaching other than traditional teaching methodologies was marked highest for teaching LOTE. Along the same line of thought, the use of technology for teaching LOTE was highly appreciated, with the belief that its proper implementation can bring effectiveness to LOTE teaching. The following discussion elaborates on LOTE teachers' views on the importance of LOTE, their pedagogical approaches, the importance of English for teaching languages, and some productive suggestions for teaching LOTE. 


\section{Benefits of LOTE}

Participants proposed that having a command of different languages can help students improve their English. This strongly supports a study by Haukås (2016) who favored multilingualism. In the words of T1:

I always tell them...French language is like English. It is not much different in terms of syntactical structure because you still have the subject, the verb. You still have to conjugate the verb and you have the complement. Therefore, if you are particular in French, your English will improve eventually.

The same views were supported by the other LOTE teachers as well: "Learning a few languages will not be a loss" (T3) and, "I think it's good because I always believe that people who acquire multilingual are good" (T2).

Speaking about multilingualism, T2 said, "Every language you learn has its own concept, beliefs and values. The more languages you acquire the better person you are because you start to think differently." Similar thoughts were added by the Mandarin lecturer, "...the more languages you learn, the more better person you are. Your perspective is different and you open for everything. Because every language has its own concepts and values" (T3).

\section{Students'Self-Motivation}

In most cases, students learned LOTE because of their own interest in learning the language. As mentioned by T1, "Usually students will choose that language in which they have interest. And when they have interest, then their learning ability is there." The same view was expressed by T2, who said, "Most of the students love Korean culture or K-pop, so their intention to learn is very strong." In the case of learning Mandarin, T3 expressed, "There are actually student who are learning this language for conversation purposes, and they want to do it as a conversational Mandarin."

\section{Importance of English}

The discussion with the interviewees traced out the importance of English. Since all the participants were from different linguistic and 
cultural backgrounds, the only commonality they had was English as their second language. While participants commented positively on the acquisition of LOTE, they emphatically mentioned the importance of English as well. According to the participants, it was not possible to teach LOTE without the use of English, especially in an environment where LOTE was not the native language of the land. Quoting T1, "Knowing the fact that we are in an environment that is not the native language spoken, so English has to be used to teach the foreign language."

Supporting the views on the importance of English, participants expressed, "In class, we have mostly Indonesian, Malaysian, Korean, and students from China. We need to use a common language, and English is that common language" (T2). Most of the time, the use of English "depends on the requirement of the students" (T3). Hence, "English is the main mode for you to teach" (T1). However, the problem arises when students are not good users of the English language:

We have difficulty when students don't know how to speak English. Because I think English is the main language to communicate for all of us.... If your proficiency in English is not good, even though I explain in English, there is no point. (T3)

T1's narrative indicated English as the main medium for communication. "In any way when you are focusing on English, it's the main communication medium. If you can't have even one common language proficiency internationally, how are you going to further in other languages!" (T1). These views were seconded by T2 who explained, "To give a confirmation on their understanding, basically I can communicate with them in a simple English." She also said, "I have to use English, and sometimes I am speaking broken English."

The use of English depended on learners' learning outcome, as elaborated by T3, who remarked, "I have to use English as 100\% in Mandarin is not doable." Therefore, "most of the time it will be English." According to the same respondent, "I am totally a zero beginner and I am not understanding what you are trying to tell me, if it is all in Chinese" (T3). T1 concurred and further explained that "we need to communicate in an effective way so that the students 
understand better before they read in that other language. That's why you need a medium and English is a medium" (T1).

\section{English for Explanation}

Even though the language teachers were not explicitly in favour of the use of English in the LOTE classroom, it was deduced from their narratives that they used English frequently for teaching LOTEs.

Quoting T2, "I give instructions in Korean first and after that translation in English." She continued, "I am speaking to them in English language sentence setting but I am replacing, changing a few words in Korean, then they understand better because it is still in English setting."

T1 expressed that although she still needed English for explanations, she preferred code mixing. "When I do mix mode, it means I will explain to them in English but at the same time I will converse with them from time to time in French as well." Related views were expressed by T3, who used English while explaining Mandarin grammar to students. "I need to give examples in English as well by telling that sequence in English is in such way, the sequence in Mandarin is in such way. You need to be careful with time word, replace word, with name word, so on."

He further added, "We need English to explain, you know, the use of certain words, meaning, grammar point." Nevertheless, the LOTE teachers used English not only to deal with grammar but also to explain most of the lessons. "If I am doing cultural class, the portion of English is a lot, compared to Chinese" (T1).

\section{English as a Hindrance}

While the importance of English cannot be denied, it is also considered a hindrance in teaching LOTE (Henry, 2010; McEown, Sawaki, \& Harada, 2017). The participating language teachers were of the view that sometimes their use of English discouraged students from practicing the new language efficiently. T2 believed that English should be completely excluded from the teaching of LOTE, only then would the student be able to learn Korean:

I actually prefer that approach [exclusion of English from Korean instruction] (laughs).... English is a kind of hindrance in their learning. Actually, they do understand depending on their intention to learn and important 
thing is intention. I want to give a message, information, the students want to understand, and actually we can communicate. Of course, the understanding level maybe a bit low, or is slow. (T2)

T3 similarly felt that English was interfering in the learning process, as "....it somehow would be going to push the student away from fully using Mandarin."

\section{Pedagogical Practices}

In most of the cases, it was noticed that teachers adopted an "experience based" teaching strategy, as expressed by T1. Similarly, the theory of constructivism claims that teachers construct their classroom practices based on their previous experiences (Fosnot, 2013; Schcolnik, Kol, \& Abarbanel, 2006).

\section{Face to face}

It was suggested by $\mathrm{T} 1$ that "language has to be face to face." According to T1, "you need to have face to face to encourage them." T1 agreed that face to face interaction was best for teaching LOTE. She mentioned her way of teaching as "sometimes I do interaction as well. I make class interactive..."

T3 seconded the views: "I think the best way for me is face to face. Language is about people talking to people. It's not talking to machine."

\section{Visualization}

The LOTE teachers found images and videos helpful for teaching languages. As T2 said, "I will use images, or body languages." In addition, "...watching Korean shows with subtitles can also help. They can understand from the context." The same practice was narrated by T3 who said, "I always show them videos in the classroom."

\section{Memorization}

Language teachers use memorizing techniques for teaching the language (Rose, 2017; Rivers, 2018). However, T1 was not in 
favour of memorization. She emphatically said, "I don't want them to memorize. I have colleagues who teach students to memorize. I don't! You need to know." She stressed, "Don't memorize. I don't believe on that much." Further along in the interview, she again negated emphatically the use of memorization, "Don't memorize! DON'T MEMORIZE! I always tell them, you memorize, you try memorize and then during oral assessment I will ask questions unexpectedly and then you will be wondering what that question is about...(laughs)."

T3 on the other hand, was of the view that there were still certain lessons for which memorization was needed. "Let's say Chinese Zodiac. The only way to do that is by memorization" (T3). In talking about his teaching techniques, he spoke positively about memorization, that "all the key words will be introducing Chinese and they have to memorize it."

Hence, the analysis showed differences in opinion regarding the use of memorization for teaching LOTE. Where some teachers sought the help of memorizing techniques, others discouraged it.

\section{Repetition}

Another much appreciated strategy for learning any language is repetition. These LOTE teachers believed that repetition can help learners learn a new language effectively. "I need to repeat in many different ways. I try to make them understand and it actually works" (T2). T1 agreed with the strategy and added that, "once they learn the words, they are able to form sentences, if we are repeating."

\section{Monolingualism}

Monolingual teaching was regarded as an effective instructional approach for teaching LOTE. Participating teachers favoured the monolingual technique, as obvious from the statement of $\mathrm{T} 1$, “... none of my notes are translated in English, everything is in French." T3 supported this view, narrating as follows:

I always encourage my students to use a proactive method. Meaning to say, yes, I speak in English but don't always ask me to translate the word for you because you need to put in efforts to find the word; you would be able to read the dictionary. (T3) 
The same technique was reinforced by $\mathrm{T} 2$, who said, "I actually prefer that approach [excluding English from my teaching] (laughs). Because previously I tried that." Somewhere in interview she further expressed that the "most effective way in terms of developing skills is actually I believe is monolingual way."

\section{Using More Than One Language}

Surprisingly, however, the same lecturer who supported monolingual teaching stated, "I use French, then I use Bahasa because I have Indonesian students. Sometimes, I use Chinese..." (T1), which shows LOTE teachers' use of bilingual instruction.

\section{Translation Method}

The method that was most adopted for teaching LOTE was translation. It was found that even though LOTE lecturers were in favour of monolingual teaching, they still used the translation technique. In the words of T2, "I give instructions or maybe explanation in Korean first and after that translation in English." T1 proposed, "you have to do translation." The same technique was supported by T3, who said, "most of them, the way they actually comprehend, they confirms, it will be doing it in the translation way."

Quoting T3 further:

...what they going to do is, they will be having this English sentence, that they will do direct translation, which happens to be not the correct one. So, in the classroom there are actually some grammar points, sentence structure that they have to memorize. (T3)

\section{Observable Behaviour}

The teachers would change their classroom strategies depending on students' observable behaviour. As T1 mentioned, "I always see the students. I will stop and ask if you have any question you can ask, but I also look at their facial expressions, body language." Similarly, T3 narrated, "The methodology is all about how you pass the message to the students but I always make sure that if they don't understand, I look at the facial expressions, I pick those. I do observe the behaviour." 


\section{Project Based Learning}

The LOTE teachers believed that students learned a language better in a collaborative environment:

In the classroom I try to give some task in group, making sentences, complete a dialogue, so they are writing sentences and find sequence in the dialogue and figuring out the use of the grammar. So basically, it is like a project based or team learning because it's a communication so they can learn in the context and they don't just read the dialogues but need to interact. (T2)

\section{Teaching School Kids}

In the words of $\mathrm{T} 1$, teaching language to new learners is, "like teaching small children. It's a game to them, like answering questions A, B, C." She mentioned what she believed to be the best way to teach a new language:

I really take my time to speed up things. Like, I give you a pen and a page and a ruler and I teach you how to hold a pen and where to put the ruler, where to draw line on the piece of paper, step by step. (T1)

T2 called beginner learners kids and added, "kids will be more happy to learn it as a play." T3 also expressed his view about language learning as follows:

In primary school or secondary school, what we have been doing with kids. Kids sometime somehow not really gadget oriented, so what we get to do is we have hardcopy, flash card, we have some engage classroom activity with them, so we will be flipping the flash card, asking them what this is, what is this character name for. (T3)

\section{Technology Enhanced Teaching}

Technology has entered all fields and language teachers have also incorporated it in their classroom teaching (Chun, Kern, \& Smith, 2016). Moreover, its benefits in teaching LOTE should be recognized as it enhances LOTE curriculum and pedagogy (Bond, Nicholson, \& Peterson, 2002). T2 shared her experience: "I am using technology, 
showing them images on internet, so it's more effective." Further in her narration, she added the incorporation of technology "by sharing some different resources like you tube links and so on." Regarding his use of technology, T3 expressed that "when it comes to learning, I am actually providing them some alternative way of doing it. Like, of course it is something online." He said, "I have been doing it via Facebook, the closed group page, where they will practice typing." T2 and T3 mentioned the introduction of the Teach Less Learn More (TLLM) concept in their organization, but since it was still in the embryonic stage (see Loo, 2018), they could not evaluate its effectiveness.

On the contrary, T1 was not much in favour of online teaching. She expressed, "I am from old school so I prefer face to face." Quoting her, "Online learning is not a very effective way." The reason she gave was poor internet connection:

...why I don't use kahoot a lot for quiz is because of the connection. As connection of the internet is also important so sometimes you setup and it is just uploading and uploading, and then you waste a lot of time in the class, just to wait for it to upload. (T1)

Data showed that T2 and T3 were also not in favour of fully integrating technology in LOTE. They respectively narrated, "I believe in blended learning actually because in language learning if we do full $100 \%$ online teaching there would be lack of communication skills. In terms of feedback and developing their linguistic skills, speaking skills we also need to get their response at the spot" (T2) and, "it is not good, using online methods" (T3).

Although not in favour of integrating technology, T1 shared that "I need to go online, to enhance, to interest or to motivate them because students of this generation, they like to do something that is a little bit different from face to face". She further added that "in terms of time management I think online is better. The students can question me by this way as some of them they need more time to digest the contents." She continued, "if I can change the setting, I prefer to do recording pronunciation, to share the pronunciation something like recording practices."

T2 shared T1's views. According to T2, "in any case I think online learning is more effective. It is more productive; I think it's better 
because this generation of students is more open to this." Another benefit of online teaching also mentioned by T2 was to "provide more time to think, to use their language skills and produce a certain length of writing," because normally "in classroom we have limited time and also they have no creativity."

T3 raised another matter regarding technology enhanced language teaching. "Every one of them, they have smartphones," and "they [students] prefer learning typing instead of writing characters." Furthermore:

...with the revolution of this technology thingie, we don't need to write, we don't need to write at all in order to learn Mandarin. They can even do voice recording, all they need to do is they just click on the button, they speak in Mandarin and the Chinese character will automatically came out and they can send the text.

Hence, the beliefs expressed by the participants regarding the pros and cons of using technology provoke the question of whether negative reactions towards technology was because of lack of appropriate training.

\section{Training}

Participants' narratives revealed a lack of technology implementation training for LOTE teachers. T3 said that they did get "so-called trainings" but "they are quite general and not related to Mandarin teaching." Most of the training organized by the institutions were regarding teaching applications. "They are quite general like some Apple workshop, like some Google classroom training workshops" (T3), "but we do not know how to use these apps for teaching lessons" (T1).

\section{Suggestions from LOTE Teachers}

A few suggestions for teaching LOTE were given by participating teachers:

i) "Foreign students should acquire certain level of English language proficiency before joining any institution, because English is the major hub of communication." (T1) 
ii) "There should be proper language teaching training for LOTE teachers." (T3)

iii) Contact time should be increased:

"It is difficult to have command on any language in only 14 weeks. We have only 3 hours face to face contact which is not enough.” (T1)

"They don't have enough contact hours to acquire the (Korean) language." (T2)

iv) For teaching any language you need to go to its roots:

"I tell them, you need to know the basic. So students say 'oh it look so childish'. It's ok, who is going to make comment, because this is your learning process, you are just at the beginning. French is not your native, you are learning, so you start from the beginning." (T1)

"Without characters, can you speak Mandarin? Yes, they do! Without Mandarin characters can you understand Mandarin? Yes, they do! So students will be asking 'why I am learning character?' I told them character is the soul of Chinese language." (T3)

v) Languages grow slowly and gradually:

"Give yourself time because the SYMPTOM of using a foreign language usually from six months to one year. Once the symptoms are there, you have reached a level. The symptom is that you will always feel like you don't understand but you will come to that point where finally you will see the whole picture." (T1)

vi) Students should use the dictionary:

"I always tell my students, dictionary is like your friend." (T1)

"You should always keep a dictionary handy, if you want to learn Mandarin language." (T3)

\section{CONCLUSIONS AND IMPLICATIONS}

The data presented affirms that although English is the main medium for communication in an international setting, it can sometimes result in delaying the process of learning a new language. This supports Henry (2010) who concluded that English interferes in the motivation to learn LOTE. The data concurs with Haukås (2016) that in multilingual classrooms, English helps in the teaching of an L3.

The participating teachers corroborate the view that the use and importance of English was due to the internationalization of 
education, despite the fact that none of them was an English teacher, or had English as their L1. The teachers believed that face-to-face and traditional teaching methodologies are still effective for LOTE teaching, while innovative technologically integrated teaching can enhance the language teaching and learning process. Moreover, their views find support in the literature, which has revealed that language learning needed longer contact hours and maximum exposure (Collins \& Munoz, 2016; Tognini, 2008; Ushioda, 2017), which can be made possible with the help of online teaching.

LOTE helps students to not only acquire an additional language but also acquaint them with the culture and people of that language (Kramsch, 2014; Foulis, 2017), as shared by the participants. It was found that the teaching of English is different from teaching LOTE, and thus should be treated differently from teaching EFL or ESL.

To conclude, LOTE teachers should consistently and meticulously analyse their teaching practices so as to devise the best possible techniques for teaching the language. They should plan more learnercentred activities and an online teaching curriculum which can help provide maximum exposure to learners.

This research contributes insights to the field of LOTE with regards to innovative learner-centred and technologically integrated pedagogy. The use of the L1 in the teaching of English has already been explored (Henry, 2010; Bartlett, 2017; McEown, Sawaki, \& Harada, 2017), whereas minimal research has been found on the use of English in teaching LOTE (Turnbull, 2018). Likewise, many studies have addressed communicative approaches for ESL with a focus on redesigning teaching skills and directing teaching to online lectures (Morat, Shaari, Abidin, \& Abdullah, 2017), whereas literature on the effectiveness of technology for LOTE teaching has been limited. As reported by the LOTE teachers, limited contact hours adversely affected students' language learning. In the case of these teachers, their institution's TLLM initiative may provide students with access to teaching material anytime, anywhere, which will help them to be more independent.

The blending of technology with the use of English in teaching LOTE finds support in constructivist theory, which focuses on construction of knowledge. As knowledge is co-constructed, mediation of technology and mediation of English play a vital role in 
the construction of knowledge between LOTE teachers and learners. The narratives indicate that the added dimension of technology and the teachers' use of English bring effectiveness to the teaching of LOTE.

This qualitative study was conducted with a small number of participants at a single site. Future research should focus on multiple sites. This study could also open new avenues for research on implementing institutional pedagogical initiatives for LOTE teaching, e.g. TLLM, and to explore the effectiveness or otherwise of integrating online teaching for LOTE.

\section{ACKNOWLEDGMENT}

This research received no specific grant from any funding agency.

\section{REFERENCES}

Anh, K. H. (2010). Use of Vietnamese in English language teaching in Vietnam: Attitudes of Vietnamese university teachers. English Language Teaching, 3(2), 119-128. doi:10.5539/elt. v3n2p119

Armstrong, N., \& Laksana, S. (2016). Internationalization of higher education: Case studies of Thailand and Malaysia. Assumption University Institutional Repository, 8(1), 102-116.

Bartlett, K. A. (2017). The use of L1 in L2 classrooms in Japan: A survey of university students preferences. Kwansei Gakuin University Humanities Review, 22, 71-80.

Bell, J. S. (2002). Narrative inquiry: More than just telling stories. TESOL Quarterly, 36(2), 207-213.

Bond, N., Nicholson, S., \& Peterson, C. (2002). Using technology in a standards-based LOTE curriculum. LOTE CED Communiqué, Issue 5. Retrieved from https://www.sedl.org/ loteced/communique/n05.html

Brown, A. V. (2009). Students' and teachers' perceptions of effective foreign language teaching: A comparison of ideals. The Modern Language Journal, 93(1), 46-60.

Chun, D., Kern, R., \& Smith, B. (2016). Technology in language use, language teaching, and language learning. The Modern Language Journal, 100(S1), 64-80. doi:10.1111/modl.12302 
Collins, L., \& Munoz, C. (2016). The foreign language classroom: Current perspectives and future considerations. The Modern Language Journal, 100, 133-147. doi:10.1111/modl.12305

Cross, R. (2010). Language teaching as sociocultural activity: Rethinking language teacher practice. The Modern Language Journal, 94(3), 433-452. doi:10.1111/j.15404781.2010.01058.x

Dörnyei,Z., \& Al-Hoorie,A.H. (2017). The motivational foundation of learning languages other than global English: Theoretical issues and research direction. The Modern Language Journal, 101(3), 445-468. doi:10.1111/modl.12408

Duff, P. A. (2017). Commentary: Motivation for learning Languages other than English in an English-dominant world. The Modern Language Journal, 101(3), 597-607. doi:10.1111/ modl.12416

Edwards, S. (2007). From developmental constructivism to sociocultural theory and practice. Journal of early childhood research, 5(1), 83-106. doi:10.1177/1476718X07072155

Elliott, J. (2005). Listening to people's stories: The use of narrative in qualitative interviews. In using narrative in social research. SAGE Research Methods, 17-35. doi:10.4135/9780857020246

Finardi, K. R., \& Rojo, R. A. (2015). Globalization, internationalization and education: What is the connection? International E-Journal of Advances in Education, 1(1), 1825. doi:10.18768/ijaedu.16488

Fosnot, C. T. (Ed.). (2013). Constructivism: Theory, Perspectives, and Practice (2nd ed.). Teachers College Press.

Gayton,A.M. (2016).A context-specific approach to L2 motivation in Anglophone settings: A first step towards theory development. The Language Learning Journal, 1-17. doi:10.1080/0957173 6.2015 .1130081

Guba, E. G., \& Lincoln, Y. S. (1994). Competing paradigms in qualitative research. In E. G. Guba, \& Y. S. Lincoln (Eds.), Handbook of qualitative research (pp. 105-117). Thousand Oaks, California: SAGE Publications.

Hangyan, S. (2016). Planning for teaching/learning Mandarin Chinese : Improvement through self-reflection and student feedback (Unpublished masters thesis). Western Sydney University, Australia.

Haukås, Å. (2016). Teachers' beliefs about multilingualism and a multilingual pedagogical approach. International Journal of 
Multilingualism, 13(1), 1-18. doi:10.1080/14790718.2015.1 041960

Henry, A. (2010). Contexts of possibility in simultaneous language learning. Using the L2 Motivational Self System to assess the impact of global English. Journal of Multilingual and Multicultural Development, 31, 149-162. doi:10.1080/01434630903471439

Hunter, S. V. (2010). Analysing and representing narrative data: The long and winding road. Current Narratives, 1(2), 44-54.

Jaramillo, J. A. (1996). Vygotsky's sociocultural theory and contributions to the development of constructivist curricula. Education, 117(1), 133-140.

Lee, H. L. (2010). Code switching in the teaching of English as a second language to secondary school students. Malaysian Journal Of ELT Research, 6(1), 1-45.

Liu, G. Q., \& Bianco, J. L. (2007). Teaching Chinese, teaching in Chinese, and teaching the Chinese. Language Policy, 6, 95117. doi:10.1007/s10993-006-9041-4

Loo, J.(2018, March 21). Teach less, learn more. Singapore Infopedia. Retrieved September 2, 2019, from http://eresources.nlb.gov. sg/infopedia/articles/SIP_2018-03-21_105159.html

Macalister, J. (2017). English and language teacher education in Malaysia: An exploration of the influences on and experiences of pre-service teachers. RELC Journal, 48(1), 53-. doi:10.1177/0033688217690936

McEown, M. S., Sawaki, Y., \& Harada, T. (2017). Foreign language learning motivation in the Japanese context: Social and political influences on self. The Modern Language Journal, 101(3), 533-547. doi:10.1111/modl.12411

Moen, T. (2006). Reflections on the narrative research approach. International Journal of Qualitative Methods, 5(4), 56-69.

Morat, B. N., Shaari, A., Abidin, M. J., \& Abdullah, A. (2017). Youtube within ESL classroom: Exploring an instructor's and her learners' experiences concerning the authenticity of language and technology use. Malaysian Journal of Learning and Instruction, Special Issue, 173-196.

Nel, N. (2016). Teaching and learning of Mandarin as a foreign language in South African schools. Perspectives in Education, 34(2), 43 - 56.

Nor, N. M., Leong, K.E., \& Ka,U. (2017). Changes in the Malaysian school curriculum from the pre-independence years until the new millennium. In Education in Malaysia. Education 
in the Asia-Pacific Region: Issues, Concerns and Prospects, (Vol. 39). Singapore: Springer.

Pugh, F. B. (2013). Multilingual label quests: A practice for the 'asymmetrical'multilingual classroom. Linguistics and Education, 142-164. Retrieved from http://dx.doi. org/10.1016/j.linged.2012.12.006

Rivers, W. M. (2018). Teaching foreign language skills (2nd ed.). Chicago, USA: University of Chicago Press.

Rose,H. (2017). The Japanese writing system: Challenges, strategies and self-regulation for learning kanji. UK: Multilingual Matters.

Saldana, J. (2016). The coding manual for qualitative researchers $\left(3^{\text {rd }}\right.$ ed). London: SAGE.

Schcolnik, M., Kol, S., \& Abarbanel, J. (2006). Constructivism in theory and in Practice. English Teaching Forum, 4, 12-20.

Stake, R. E. (1995). The art of case study research. Thousand Oaks, USA: SAGE.

Steiner, V. J., \& Mahn, H. (1996). Sociocultural approaches to learning and development: A Vygotskian framework. Educational Psychologist, 31(3), 191-206. doi:10.1080/004 61520.1996 .9653266

Tan, C. H., \& Abbas, D. (2009). The 'Teach Less, Learn More' initiative in Singapore: New pedagogies for Islamic religious schools? KEDI Journal of Educational Policy, 6(1), 25-39.

Thompson, G. L., \& Harrison, K. (2014). Language use in the foreign language classroom. Foreign Language Annals, 47(2), 321337. doi:DOI: 10.1111/flan.12079

Tognini , R. (2008). Interaction in languages other than English classes in western Australian primary and secondary schools: Theory, practice and perceptions (Unpublished doctoral thesis). Edith Cowan University, Australia.

Trahar, S. (2014). 'This is Malaysia. You have to follow the custom here': Narratives of the student and academic experience in international higher education in Malaysia. Journal of Education for Teaching, 40(3), 217-231 . doi:10.1080/0260 7476.2014 .903023

Turnbull, B. (2018). The use of English as a Lingua Franca in the Japanese second language classroom. Journal of English as a Lingua Franca, 7(1), 131-151. doi:10.1515/jelf-2018-0006

Ushioda, E. (2017). The impact of global English on motivation to learn other languages: Toward an ideal multilingual self. The Modern Language Journal, 101(3), 469-483. doi:10.1111/ $\operatorname{modl} .12413$ 
Webster, L., \& Mertova, P. (2007). Using narrative inquiry as a research method. London: Routledge Taylor \& Francis.

Yazan, B. (2015). Three approaches to case study methods in education: Yin, Merriam, and Stake. The Qualitative Report, 20(2), 134-152. Retrieved from http://nsuworks.nova.edu/tqr/ vol20/iss $2 / 12$

Yin, R. K. (2011). Qualitative research from start to finish. New York: The Guilford Press. 